present a case under his observation in which a tratuma had apparently started the growth. The patient had been thrown to the ground by a passing wagon. Within ten or twelve days she developed a paresthesia in the left upper extremity, which gradually became more severe until she could no longer distinguish between hot and cold, and now, two months later, she presented definite symptoms of a central tumor of the spinal cord which was extending upwards.

Probably in most of these cases, Dr. Hunt said, there was some central gliosis or other defect which served as a basis for the growth.

Dr. Schlapp, in closing, in reply to Dr. Fraenkel, said that throughout the cord there were areas where the central canal was found to be obliterated. The gliosis, however, extended down the posterior septum and was not connected with the central canal. Cases had been recorded, the speaker said, where the cavity or gliosis was not connected in any part of the cord with the central canal. Dr. Schlapp said he did not look upon a gliosis as a tumor formation. In the case he reported he believed that the neuro-epithelioma had its origin in the trauma incident to the operation.

The following officers were elected for the ensuing year: President, Dr. J. Ramsay Hunt; first vice-president, Dr. B. Onuf; second vicepresident, Dr. L. Pierce Clark; corresponding secretary, Dr. S. Ely Jelliffe; recording secretary and treasurer, Dr. Edwin G. Zabriskie.

\title{
PHILADELPHIA NEUROLOGICAL SOCIETY
}

December I8, I908

The Vice-President, DR. John K. Mitchelt, in the Chair

\section{A CASE OF HEMATOMYELIA AND A CASE OF} SYRINGOMYELIA

\section{By Augustus A. Eshner, M.D.}

Case I. A woman, 25 years old, who had for two or three years rather constantly backache, was suddenly seized with severe pain in the lumbo-sacral region, lasting for three or four days, and followed by numbness and muscular weakness in the lower extremities, and for five weeks by loss of control of the sphincters. There was no loss of consciousness. While under treatment pneumonia developed, and this was followed by abscess of the left kidney requiring operation. During the course of this illness the patient sustained a burn in the hypogastric region, of which at the time she had no consciousness. Improvement gradually took place, and when the patient came under observation some eighteen months after the onset of her illness she still complained of loss of power and numbness in the lower extremities, with girdle sense about the level of the umbilicus. The gait was awkward and cautious, while station was a little uncertain. The knee-jerks were exaggerated, the right in slightly greater degree than the left. The ankle-jerks were active. Abortive ankle-clonus could be elicited on the left, while there was some rigidity at the right ankle-joint and overextension of the great toe of the right foot. The Babinski reflex was present on both sides. Tactile sensation was preserved everywhere, while recognition of the touching object and of heat and cold and of pain was absent on the trunk below the level of a line passing midway between the umbilicus and the ensiform cartilage 
and on the extremities. There was no evident muscular wasting and no fascicular twitching. There was occasional active involuntary jerking of one part or another. The upper extremitics were entirely uninvolved and there was no deformity of the spine. Micturition was deranged, there being at times difficulty in expulsion of urine and at other times deficient control. Eyesight, hearing, taste and smell were subjectively unimpaired. The eyes presented nothing abnormal. The pupils were equal, regular, reactive to light and in convergence and the media were clear and the fundi normal. Sexual desire was wanting, and there was occasional headache, but no nausea or vomiting. There was no other evidence of visceral disease. The patient had had measles and whooping-cough in childhood, but she knew of no difficulty in learning to walk, and she had been an average pupil at school and been able to participate in ordinary play. Menstruation had set in at I4 and was regular. The patient had had a stillborn child, but no miscarriage. There was no history or evidence of syphilis. The father was dead from an unknown cause, the mother from pneumonia. A brother was in good health, and a sister had died from gallstones. The patient was the second child and she knew of no difficulty in birth on the part either of herself or of other children in the family. There was no history of traumatism.

We have in this case the sensory dissociation phenomenon, together with other symptoms, of syringomyelia, but the history of sudden invasion and the subsequent improvement in the symptoms make it seem more likely that we have to do rather with a hemorrhage into the spinal cord, although it must be admitted there was no obvious predisposing cause for such an occurrence.

Case 2. A woman, 27 years old, who had been separated from her husband for two years, complained of loss of sensation in the entire right upper extremity, which felt as though it were wrapped in some substance. There was also some loss of sensation in the left upper extremity. The patient frequently burned herself about the right hand or arm without consciousness of the occurrence and the wounds vere slow in healing. She related that some eight years previously, while slaking lime, she had burned her hands and was distinctly conscious of the resulting pain. Subsequently the hands were exposed to cold and later the loss of sensation was noted. The hands became swollen at times and the fingers were said to be shorter and thicker than they had been; the finger-nails. were rough and thick and partly deformed, but some of these changes may have been due to the coarse manual labor the patient was compelled to perform. On examination tactile, painful and thermal sensibility appeared to be absent throughout the entire right upper extremity, although the patient would at times jerk the member abruptly when it was pricked sharply. Thermal sensibility was imperfect in the left upper extremity, but the other forms of sensibility were preserved here as elsewhere. The gait was somewhat awkward and the station slightly swaying when the eyes were closed. The knee-jerks were exaggerated. The soles of the feet were extremely sensitive to irritation, the slightest touch on the sole being quickly followed by sharp flexion of the foot and extension of the great toe. The sphincters were under perfect control, and the pupils exhibited no abnormality. There was no undue laughter or weeping and there was no history of shock, emotional or physical. Headache occurred occasionally, but other organic functions were well performed. The patient had had a number of the diseases of childhood, as well as smallpox at 6 , cholera at $I I$ and erysipelas at 24 . Menstruation had set in at I6 
and was always regular and painless. She had given birth to a child that died at the age of four months without apparently having been ill. There had been no miscarriage. There was nothing in the family history having any bearing on the patient's illness.

While the total absence of sensibility of all forms in the right upper extremity suggests the possible presence of hysteria, the lack of tactile sense, especially when taken in connection with the exaggeration of the reflexes in the lower extremities, does not preclude the diagnosis of syringomyelia.

Dr. Mills said it is possible to have syringomyelia of traumatic origin but it is uncommon. Dr. Mills alluded to a case at the University Hospital which appeared to be of that nature, but it seemed to him that the casc of Dr. Eshner could be explained on the thcory of a hematomyelia, espccially because of the suddenness.

\section{A CASE OF PROGRESSIVE MUSCULAR ATROPHY WITH REMARKABLE IMPROVEMENT}

\section{By J. K. Mitchcll, M.D.}

The interest of the patient presented lies in two points-the diagnosis and the unusually good results of treatment. The history is briefly as follows: G. S., xt. 24 years, an autonobile mechanic, has no points of interest in the personal or family history up to the beginning of the condition from which he now suffers, cxccpt scarlet fever in his ninth year, during which he is said to have had meningeal symptoms. Not long after some deformity or weakness of the left foot was noticed and an increasing symmetrical atrophy all over the body developed slowly from that time. At 18 years the little toe of the left foot was frost-bitten and had to be amputated, and, although it healed, an open ulccr afterwards developed and has never closed.

He has been at work until he came to the Orthopedic Hospital for treatment of this ulcer and was referred from the surgical clinic to the neurological service for care of his atrophic trouble.

He has, very distinct, general wasting, affecting all his muscles except those of the face. Sensation in all forms and everywhere is normal except on the toes, where it is slightly diminished to touch. The knee-jerk is lost, the skin reflexes are present, there are no abnormal reflexes. The atrophy of the foot muscles has resulted in a slight pes cavus and this, with his weakness, causes a swaying gait, but his station is perfect. He has no pain or tenderness anywhere. Electric examination of the muscles developed the interesting fact that there was no reaction of degeneration, but an evenly distributed quantitative reduction to both galvanism and faradism, not of very high degree.

The question of diagnosis is interesting here. At first polyneuritis seemed most likely in view of the history of infectious disease and of the legs having shown the earliest signs of trouble, as is usual in infectious polyneuritis. The continuation and slow spread of the trouble without pain, seem to render this improbable. The character of the onset, the subsequent history, and the electric contractility also exclude the possibility of chronic poliomyelitis. Nor can we think it amyotrophic lateral sclerosis in view of the absence of any involvement of the pyramidal tracts, usually found degenerated in that disorder. Simple weakness, widely disseminated progressive wasting, with loss of deep reflexes in the wasted parts, force on us the conclusion of progressive muscular atrophy. 